\title{
A Fundamental Investigation on the Structural Dynamics of Model Siloxane Networks under Extreme Pressure
}

\author{
Stephen J. Harley (PI), James P. Lewicki
}

Physical \& Life Sciences

FY2013 Lab Wide Research Proposal

Laboratory Directed Research and Development Program

LLNL-TR-640514 
This document was prepared as an account of work sponsored by an agency of the United States government. Neither the United States government nor Lawrence Livermore National Security, LLC, nor any of their employees makes any warranty, expressed or implied, or assumes any legal liability or responsibility for the accuracy, completeness, or usefulness of any information, apparatus, product, or process disclosed, or represents that its use would not infringe privately owned rights. Reference herein to any specific commercial product, process, or service by trade name, trademark, manufacturer, or otherwise does not necessarily constitute or imply its endorsement, recommendation, or favoring by the United States government or Lawrence Livermore National Security, LLC. The views and opinions of authors expressed herein do not necessarily state or reflect those of the United States government or Lawrence Livermore National Security, LLC, and shall not be used for advertising or product endorsement purposes.

This work performed under the auspices of the U.S. Department of Energy by Lawrence Livermore National Laboratory under Contract DE-AC52-07NA27344. 


\section{Table of Contents}

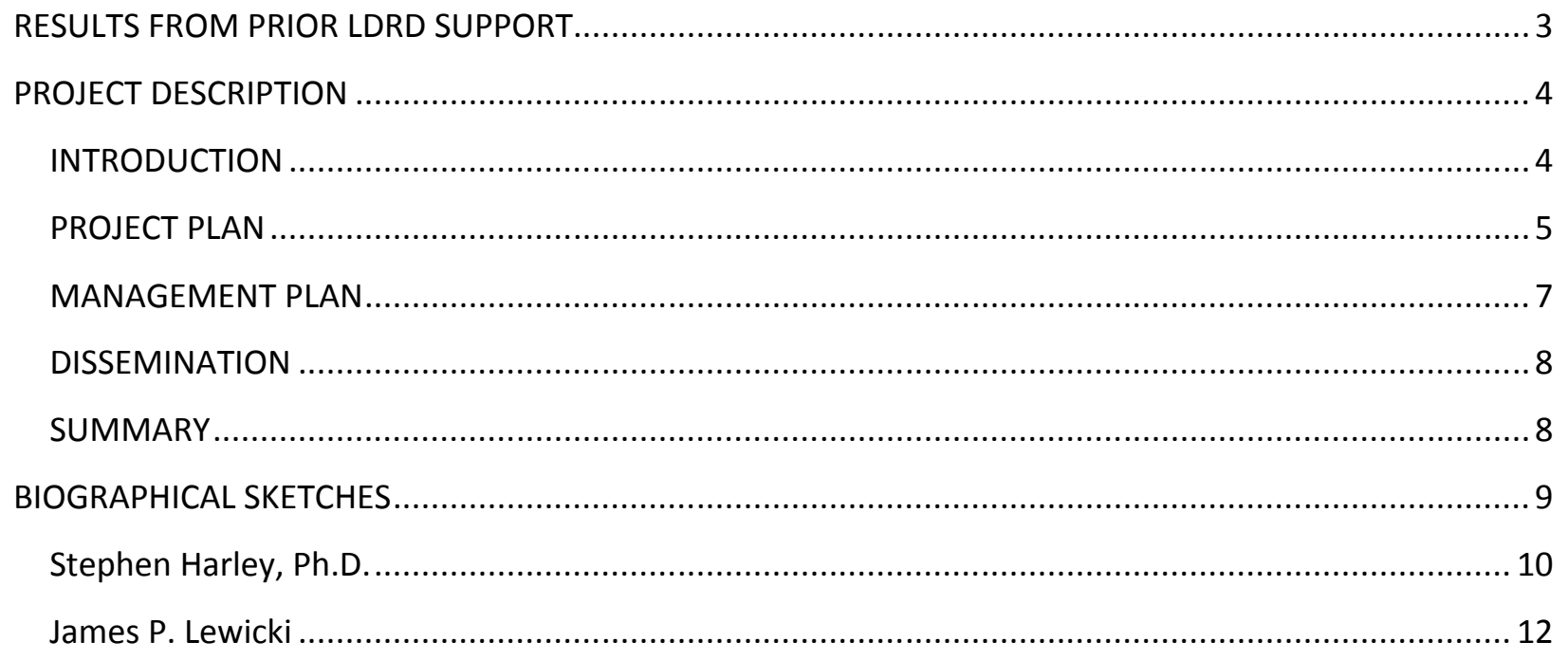




\section{RESULTS FROM PRIOR LDRD SUPPORT}

The PI, Stephen Harley, has not previously been PI of an LDRD; however, Stephen provided analytical support for the multifunctional materials focus area of the Chemistry and Materials Science Directorate ER-LDRD (12-ERD-046) "Predicting Weapon headspace gas atmosphere." The focus of this element was to develop a code capable of predicting weapon headspace atmosphere in support of aging assessment. Part of this research involved developing experimental and computational methodologies to assess the aging characteristics of these materials. Stephen aids in both the experimental design to obtain relevant parameters and the computational code generation. This LDRD is ongoing and is in year 2, there are 3 publications currently being written and 1 has been accepted:

1. Harley, S. J.; Glascoe, E. A.; Maxwell, R. S., Thermodynamic Study on Dynamic Water Vapor Sorption in Sylgard-184. J Phys Chem B 2012, 116 (48), 14183-14190. 


\section{PROJECT DESCRIPTION}

\section{INTRODUCTION}

Everyone is familiar with the elastic properties of a butyl rubber racket ball, bouncing freely when thrown against a wall. People are similarly aware that when submerged in liquid $\mathrm{N}_{2}$ the same ball becomes brittle and hard, shattering when thrown against a wall. This is a result of butyl rubber undergoing a phase transition as it crossed a critical temperature, $\mathrm{T}_{\mathrm{g}}$. While the thermal dependence of these phase transitions has been extensively explored, other state variables such as pressure have largely been ignored. However, this gap in our knowledge base does not indicate that pressure has no influence on the morphological state of polymers; rather, it's simply been overlooked. Mechanical testing is the dominant method to characterize polymers up to approximately $1 \mathrm{MPa}[1]$ and diamond anvil experiments span $1 \mathrm{GPa}$ onward[2]. There is a clear gap in our knowledge base where pressure induced changes have not been explored. Phase transitions are not benign subtle variations in a polymer's properties; rather they induce drastic changes in the materials mechanical properties. Consequently, pressure induced crystallization could result in a polymeric part going out of spec. Additionally network failure or unknown degradative mechanisms could arise. At this point, we are looking at an entirely unexplored area of materials behavior.

Functional components based on Poly(siloxane) elastomers are ubiquitous in their use in the fields of engineering, aerospace, defense and the biomedical industries. And as such, this diverse class of material often find application in extreme environments of temper ature and/or pressure. While the effects of temperature on polysiloxanes has been well studied and their behavior is well understood, it is startling to note that we know practically nothing about this class of materials behavior or eventual fate at extreme pressures. Consequently no predictive estimate of the lifetime of failure of a polysiloxane material can be offered in the MPa-GPa region, where this critical knowledge gap lies.

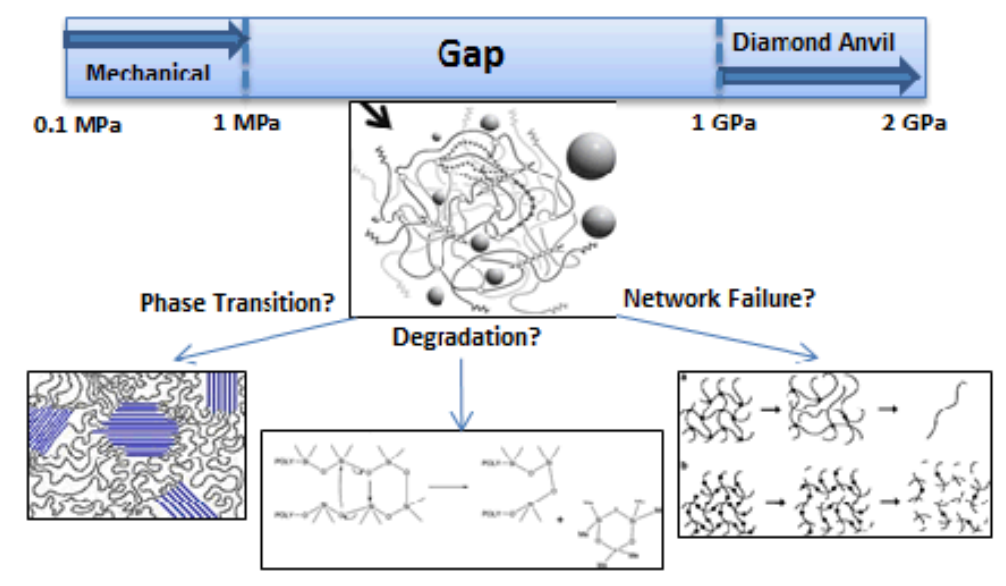

Figure 1: Schematic representation of our gap in testing capabilities for polymeric materials. 
Nuclear Magnetic Resonance Spectroscopy (NMR) and Broadband Dielectrics Spectroscopy (BDS) are sensitive techniques to assess both the long and short range motions in polymeric materials.[3-9] Incorporation of high pressure probes to these spectroscopies has already been established in the solution state by the PI.[10-13] In addition, a preliminary experiment on an model PDMS network did yield a sudden change in relaxation that could indicate a phase transition, see Fig. 2. Further investigations were not pursued due to the lack of time available to the team. We have the materials, expertise, and equipment to start a rigorous scientific study, funding is sought to cover the time needed for this effort.

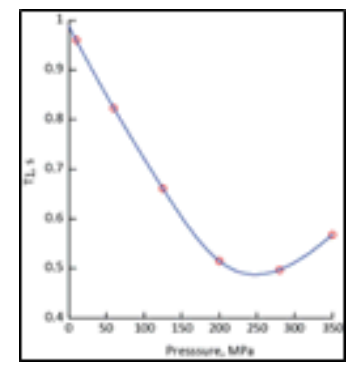

Figure 2: Preliminary results suggest pressure induced phase change at $200 \mathrm{MPa}$.

\section{PROJECT PLAN}

\section{Objective 1: Hardware Development}

Currently we have two functional high pressure probes both adapted for NMR analysis. The first is a large variable temperature probe having dimensions similar to typical NMR probes. The probe circuit coil will need to be tuned to the desired frequency (400 MHz) and sized according to the samples geometry. The PI does not envision any problems with this as the PI has over 8 years of NMR hardware experience. This system has a maximum working pressure of $350 \mathrm{MPa}$. J. Lewicki (an expert in the field of applied polymer dielectric spectrometry) will support the modification of this probe to accommodate compact, inter-digit electrodes and the circuits required to interface it with a broadband dielectric spectrometer, allowing dielectric reloxmetry data of materials of study to be acquired under pressure and in real time.
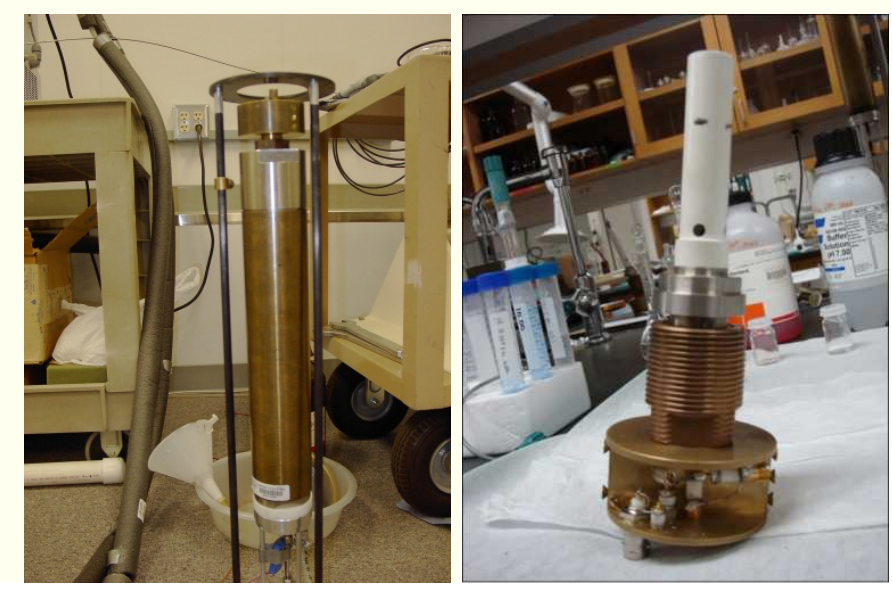

Figure 3: High pressure probe capable of reaching $350 \mathrm{MPa}$.

The second probe is a much more compact variant that allows for hydrostatic pressures up to 2 $\mathrm{GPa}$. It has been pressure tested with an academic collaboration at UC Davis and NMR spectra for ${ }^{29} \mathrm{Si}$ solution speciation has been taken. As with the system above, circuit modifications to achieve a $400 \mathrm{MHz}$ resonance does not present a challenge. The team has significant experience 
with microcoil NMR and adaptation to dielectrics will be similar to the challenges mentioned above. A safety note will need to be written to take spectra here under our existing IWS.

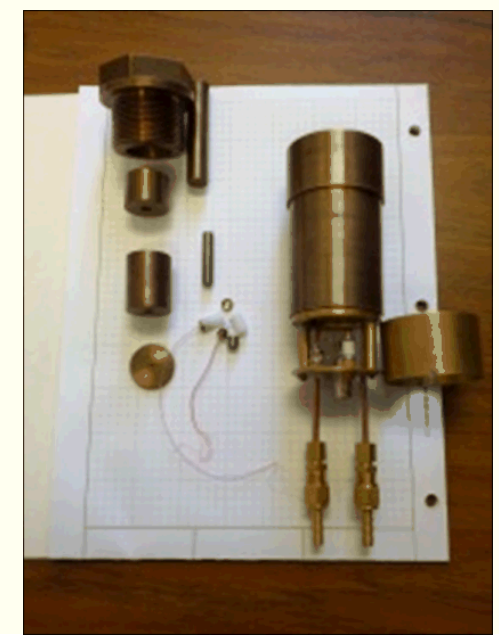

Figure 4: High pressure probe capable of reaching $2 \mathrm{GPa}$.

\section{Objective 1 Key Deliverables:}

Year 1: Adapt hardware to interface with our spectrometers

Year 2: Continue with maintenance and implement changes as needed.

\section{Objective 2: Demonstrate ability to monitor phase changes}

The co-PI has significant experience in synthetically producing model PDMS networks and has optimized the formulation chemistry. We will use these networks as the focus of our investigation. The benefit of these networks is a control in the physical chemistry. This is to say we can understand any bulk morphological changes as a direct result of the PDMS undergoing a phase transition thereby decoupling the effects of fillers typically encountered in commercial formulations. This allows us to understand possible phase transitions from a fundamental scientific perspective.

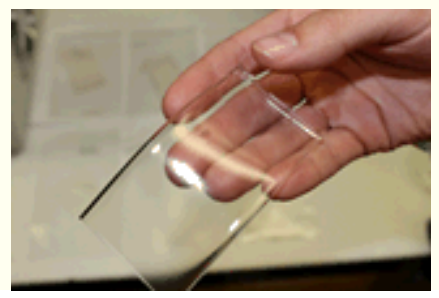

Figure 5: Example of a model PDMS network where the cure chemistry has been optimized.

These model networks spanning both above and below the entanglement molecular weight of PDMS will be cast into appropriate sample containers and inserted into the high pressure vessels. Pressure will be varied systematically from approximately $100 \mathrm{kPa}$ to $2 \mathrm{GPa}$ and evidence for phase transitions will be monitored with the aforementioned spectroscopies. In dielectric spectroscopy a sudden shift in the $\alpha$ and $\beta$ relaxation frequencies would be indicative of a phase 
transition. In NMR spectroscopy the relaxation properties of the PDMS will be investigated with a combination of classic inversion recovery and CPMG pulse sequences as well as more advanced multiple quantum experiments. It is well established that the relaxation properties of the material are directly related to the motional dynamics of the material.[14] Therefore any drastic stiffening or softening of the material (indicative of a phase change) would be clearly visible in these spectroscopies.

The one possible source for failure in these experiments is the lack of any phase change in the span of pressures investigated. However, we have preliminary evidence (Fig. 2) that indeed there will be.

\section{Objective 2 Key Deliverables:}

Year 1: Test ideal network with NMR

Year 2: Test ideal network with Dielectrics and compare

\section{Objective 3: Interpret data towards broader implications in other materials}

Model networks provide an excellent foundation for our understanding of pressure related morphological changes. However, these model materials not have the necessary mechanical properties for commercial implementation. Fillers are often added to achieve desired mechanical properties. As part of phase two of this project model networks will be synthetically produced will varying levels of filler loading. Then these materials will be subjected to the procedures outlined in objective 2 and shifts in phase changes will be sought.

This data will directly aid in the tailoring of materials to be more resistant to pressure changes.

\section{Objective 3 Key Deliverables:}

Year 1: N/A

Year 2: Test more complex networks

\section{MANAGEMENT PLAN}

Principal Investigator Stephen Harley has extensive experience leading small teams in high pressure research will have direct responsibility for ensuring that goals, deliverables and milestones are met throughout the course of the project. S. Harley will also be technical lead in the use, modification of the high pressure equipment and will be scientific lead on NMR spectroscopy. James Lewicki will be responsible for the synthesis the model networks and lead the dielectric spectroscopy effort. Evaluation of all data will be done as a group, communication with the team will occur primarily through regularly scheduled project meetings to discuss project status and results and facilitate the integration of the computational and experimental aspects of the project. We will obtain valuable peer review through publication of results in scientific journals and presentations at conferences, well as other national scientific venues.

We anticipate that the initial results obtained with internal LDRD investment will serve as a foundation upon which we will transition to sponsor funds to expand to a much larger 
investigation of materials pertinent to the mission of the lab. This capability will be broadly applicable to any solid or liquid and will provide increased understanding of how materials behave in this little understood pressure region. With the fundamental understanding of the chemistry that governs pressure induced phase transitions, a better selection of materials to mitigate unwanted morphological changes can be made.

\section{DISSEMINATION}

This work will be published in peer review journals and presented at professional conferences.

\section{SUMMARY}

Poly(dimethylsiloxane) elastomers are ubiquitous in their application as key components in a range of (often extreme) environments. and as such, they often experience pressures in a region where we do not understand their physical response and therefore can offer no predictive estimate of lifetime of failure. We are proposing a fundamental scientific investigation of the pressure induced morphological changes in model PDMS networks. Both NMR and BDS spectroscopies will be used to interrogate pressure induced changes and meaningful phase relations will be sought. The addition of filler to the networks will be used as an attempt to engineer the network to be more resistant to pressure changes. We have the equipment, model networks and expertise to start this project immediately; funding is sought as an investment in our time allocation.

\section{REFERENCES CITED}

1. Tyagi, D., et al., Segmented Organosiloxane Copolymers .2. Thermal and Mechanical-Properties of Siloxane Urea Copolymers. Polymer, 1984. 25(12): p. 1807-1816.

2. Bassett, D.C., S. Block, and Piermari.Gj, High-Pressure Phase of Polyethylene and Chain-Extended Growth. Journal of Applied Physics, 1974. 45(10): p. 4146-4150.

3. Chien, A., et al., Characterization of radiation-induced aging in silica-reinforced polysiloxane composites. Radiation Physics and Chemistry, 2000. 59(5-6): p. 493-500.

4. Mason, H.E., et al., Probing the Surface Structure of Divalent Transition Metals Using Surface Specific Solid-State NMR Spectroscopy. Environmental Science \& Technology, 2012. 46(5): p. 2806-2812.

5. Maxwell, R.S., et al., Radiation-induced cross-linking in a silica-filled silicone elastomer as investigated by multiple quantum H-1 NMR. Macromolecules, 2005. 38(16): p. 7026-7032.

6. Hadi, Z.M.A., et al., Methods Available for Measurement of Dielectric-Relaxation in Megahertz and Gigahertz Frequency Ranges. Advances in Molecular Relaxation Processes, 1975. 6(4): p. 267-286.

7. Lochhead, R.Y. and A.M. North, Dielectric-Relaxation in Solutions of 2 Poly(Alkyl Isocyanate)S. Journal of the Chemical Society-Faraday Transactions li, 1972. 68: p. 1089-\&. 
8. North, A.M., Dielectric-Relaxation in Polymers with Particular Reference to 2-Phase Systems. Journal of Polymer Science Part C-Polymer Symposium, 1975(50): p. 345-358.

9. North, C.E., et al., Dielectric constant reduction using porous substrates in finline millimetre and submillimetre detectors. Millimeter and Submillimeter Detectors and Instrumentation for Astonomy Iv, 2008. 7020.

10. Harley, S.J., H.E. Mason, and J.W. Casey, A 31P NMR investigation of the CoPi water-oxidation catalyst. Chemistry, A European Journal Communication, 2012.

11. Harley, S.J., C.A. Ohlin, and W.H. Casey, Geochemical kinetics via the Swift-Connick equations and solution NMR. Geochimica et Cosmochimica Acta, 2011. 75(13): p. 3711-3725.

12. Harley, S.J., et al., The Pressure Dependence of Oxygen Isotope Exchange Rates Between Solution and Apical Oxygen Atoms on the [UO(2)(OH)(4)](2-) Ion. Angewandte Chemie-International Edition, 2011. 50(19): p. 4467-4469.

13. Johnson, R.L., et al., Multinuclear NMR Study of the Pressure Dependence for Carbonate Exchange in the UO(2) (CO(3) )(3) (4-) (aq) lon. Chemphyschem, 2011. 12(16): p. 2903-6.

14. Liu, N.I. and J. Jonas, High-Pressure Nmr-Study of Molecular Motions and Glass-Transition in Several Elastomers. Journal of Magnetic Resonance, 1975. 18(3): p. 444-454.

\section{BIOGRAPHICAL SKETCHES}




\section{Stephen Harley, Ph.D.}

Energetic Materials Center

Lawrence Livermore National Laboratory

925.422 .5115

harley2@1lnl.gov

\section{(a) Professional Preparation}
University of California - Davis
Chemical Engineering
B.S., 2006
University of California - Davis
Analytical Chemistry
Ph.D., 2009
Lawrence Livermore National Lab CSD
2011 (current)

\section{(b) Appointments}

March 2013 - Current: Staff Researcher, Lawrence Livermore National Lab, Chemical Sciences Division, Energetic Materials Center.

April 2011 - March 2013: Post-Doctoral Researcher, Lawrence Livermore National Lab, Chemical Sciences Division, Energetic Materials Center.

Feb. 2010 - April 2011: Post-Doctoral Researcher, University of California - Davis, Chemistry Department, Casey Group. Designed high pressure NMR hardware, studied aqueous actinide ligand exchange and characterized new water splitting catalyst using a broad spectrum of analytical techniques.

Sept. 2006 -Dec. 2009: Graduate Student, University of California - Davis, Chemistry Department, Augustine Group. Developed patented noninvasive wine authentication protocol using custom designed dielectric and diamagnetic impedance spectroscopy.

Sept. 2002 - June 2006: Undergraduate Researcher, University of California - Davis, Chemical Engineering Department. Research on the functionalization of silicon nanoparticles, cavity ring down spectroscopy and sonoluminescence.

\section{(c) Awards}

Office of Naval Research Award: 2006.

Borge Fellowship: $2006-2008$.

\section{(d) Publications}


Related to proposed project:

1) Harley, S. J.; Ohlin, C. A.; Johnson, R. L.; Panasci, A. F.; Casey, W. H., The Pressure Dependence of Oxygen Isotope Exchange Rates Between Solution and Apical Oxygen Atoms on the [UO(2)(OH)(4)](2-) Ion. Angew Chem Int Edit 2011, 50 (19), 4467-4469.

2) Mason, H. E.; Harley, S. J.; Maxwell, R. S.; Carroll, S. A., Probing the Surface Structure of Divalent Transition Metals Using Surface Specific Solid-State NMR Spectroscopy. Environ Sci Technol 2012, 46 (5), 2806-2812.

3) Johnson, R. L.; Harley, S. J.; Ohlin, C. A.; Panasci, A. F.; Casey, W. H., Multinuclear NMR Study of the Pressure Dependence for Carbonate Exchange in the UO(2) $(\mathrm{CO}(3)$ )(3) (4-) (aq) Ion. Chemphyschem 2011, 12 (16), 2903-6.

4) Harley, S. J.; Ohlin, C. A.; Casey, W. H., Geochemical kinetics via the Swift-Connick equations and solution NMR. Geochimica et Cosmochimica Acta 2011, 75 (13), 37113725.

5) Ohlin, C. A.; Harley, S. J.; McAlpin, J. G.; Hocking, R. K.; Mercado, B. Q.; Johnson, R. L.; Villa, E. M.; Fidler, M. K.; Olmstead, M. M.; Spiccia, L.; Britt, R. D.; Casey, W. H., Rates of Water Exchange for Two Cobalt(II) Heteropolyoxotungstate Compounds in Aqueous Solution. Chem-Eur J 2011, 17 (16), 4408-4417

Other significant publications:

1) Harley, S. J.; Lim, V.; Augustine, M. P., Using low frequency dielectric absorption to screen full intact wine bottles. Anal Chim Acta 2011, 702 (2), 188-94.

2) Harley, S. J.; Lim, V.; Stucky, P. A.; Augustine, M. P., Using low frequency full bottle diamagnetic screening to study collectible wine. Talanta 2011, 85 (5), 2437-2444.

3) Harley, S. J.; Lim, V.; Augustine, M. P., Application of bivariate statistics to full wine bottle diamagnetic screening data. Talanta 2012, 89, 484-489.

4) Harley, S.J., Lim, V., et al. (Full Patent Submitted: 12/927,411 PCT PCT/US2010/002962). An Authentication Device for Full Intact Wine Bottles. United States Patent and Trademark Office, The Regents of the University of California. 1.

5) Lim, V.; Harley, S. J.; Augustine, M. P., Noninvasive Identification of Tainted Corks in Full Intact Wine Bottles: A Low-Pressure Room Temperature Study. Am J Enol Viticult 2011, 62 (3), 291-297. 


\author{
James P. Lewicki \\ Forensics and Assessments Support \\ Lawrence Livermore National Laboratory \\ 423-1115 \\ Lewicki1@1lnl.gov
}

\title{
(a) Professional Preparation
}

A list of the individual's undergraduate and graduate education and postdoctoral training as indicated below:

University of Strathclyde, Glasgow Chemistry Msci, 2004

University of Strathclyde, Glasgow Physical Chemistry Ph.D , 2008

University of Strathclyde, Glasgow Polymer Chemistry 2008-2009

\section{(b) Appointments}

Dec 2011 to Present: Full time scientific research staff member, Lawrence Livermore National Laboratory, Chemical Sciences Division, Forensics and Assessments Support Group

Oct. 2009 - Dec. 2011: Post-Doctoral Researcher, Lawrence Livermore National Laboratory, Chemical Sciences Division, Forensics and Assessments Support Group.

Jan. 2008 - Sept. 2009: Post-Doctoral Research Fellow, University of Strathclyde, Glasgow Physical Polymer Chemistry Section.

June 2002 - June 2003: Research and Development Chemist, ICI Imagedata, Brantham, Essex, UK

\section{(d) Publications}

i) Related to the proposed project

Lewicki JP, Mayer, BP, Alviso CT, and Maxwell, RS. "Thermal Degradation Behavior and Product Speciation in Model Poly(dimethlysiloxane) Networks" Journal of Inorganic and Organometallic Polymers and Materials 2012, 22, 636-645. 
Lewicki, JP, Mayer BP, Albo, RLF, Harley, SJ, Mason, HE, Alviso, CT and Maxwell RS. "NMR and Thermal Analytical Investigations of Structure Property Relationships in End-Linked Model PDMS Networks" Abstracts of Papers of the American Chemical Society 2012

Mayer, BP, Lewicki JP, Weisgraber T, Small W, Chinn SC and Maxwell RS, "Linking Network Microstructure to Macroscopic Properties of Siloxane Elastomers Using Combined Nuclear Magnetic Resonance and Mesoscale Computational Modeling" Macromolecules 2011, 44, 81068155.

Lewicki JP, Maxwell RS, Patel M, Herberg J, Liggat JJ, and Pethrick RA. "Effects of metacarborane on segmental dynamics in a bimodal PDMS network" Macromolecules 2008, 41, 9179-9186.

Lewicki JP, Liggat JJ, Hayward D, Pethrick RA. "Degradative Thermal Analysis and Dielectric Spectroscopy Studies of Aging in Polysiloxane Nanocomposites" Chapter 21 pp. 239-254. American Chemical Society Symposium Series Vol. 1004, Polymer Degradation and Performance. Ed. M. Celina 2009.

Lewicki JP, Liggat JJ, Patel M, Pethrick RA, Rhoney IR. "Investigating the Ageing Behaviour of Polysiloxane Nanocomposties by Degradative Thermal Analysis" Polymer Degradation and Stability 2007, 93, 158-162.

ii) Other significant publications

Lewicki, JP, Albo RLF, Alviso, CT and Maxwell, RS. "Pyrolysis-gas chromatography/mass spectrometry for the forensic fingerprinting of silicone engineering elastomers" Journal of Analytical and Applied Pyrolysis 2013, 99, 85-91

Stadermann, M, Kucheyev, SO, Lewicki, JP and Letts SA, "Radiation Tolerance of Ultra-Thin Formvar Films" Applied Physics Letters 2012 101, 071908 (2012); doi: 10.1063/1.4746403

Worsley, MA, Kucheyev, SO, Mason, HE, Merrill, MD, Mayer BP, Lewicki, JP, Valdez CA, Suss, ME, Stadermann, M, Pauzauskie, PJ, Satcher, JH, Biener, J, Baumann, TF. "Mechanically robust 3D graphene macroassembly with high surface area" Chemical Communications 2012, 48, 8428-8430.

Lewicki JP, Pielichowski K, Tremblot P, Janowski B, Todd D and Liggat JJ. "Thermal Degradation Studies of Polyurethane/POSS Nanohybrid Elastomers" Polymer Degradation and Stability 2010, 95, 1099-1105.

Lewicki JP, Liggat JJ and Patel M. "The Thermal Degradation Behaviour of Polydimethylsiloxane/Montmorillonite Nanocomposites" Polymer Degradation and Stability 2009, 94, 1548-1557. 
Lewicki JP, Liggat JJ, Patel M, Pethrick RA, Rhoney IR. "Investigating the Ageing Behaviour of Polysiloxane Nanocomposties by Degradative Thermal Analysis" Polymer Degradation and Stability 2007, 93, 158-162. 